\title{
Planos Estratégicos Municipais de Turismo do Estado de Santa Catarina - Roteiros Turísticos Regionais: um estudo
}

\author{
Strategic Plans of Municipal Tourism of the State Santa Catarina - Itineraries Regional: a \\ study
}

\section{Municipal de Turismo Planes Estratégicos del Estado de Santa Catarina - Itinerarios Turístico Regional: un estudio}

Susana Severino ${ }^{1}$

Simone Tomasulo ${ }^{2}$

\section{Resumo}

Este artigo tem como objetivo identificar quais as cidades dos Roteiros Regionais de Santa Catarina elaborou o plano estratégico do turismo municipal e avaliar o método de planejamento aplicado a documentos já concluídos. $\mathrm{Na}$ análise, foi investigada a existência de dois conceitos: "planejamento estratégico", segundo o autor Kotler (1998) e "O planejamento do turismo" Barretto (2005). A metodologia para o desenvolvimento deste estudo foi a pesquisa descritiva, qualitativa e quantitativa. Os procedimentos foram pesquisa bibliográfica, documental. $\mathrm{Na}$ coleta de dados utilizou-se o questionário. Os principais resultados demonstraram que o planejamento estratégico do turismo precisa melhorar no estado. Os principais resultados foram: a dependência de recursos federais e estaduais para os planos e projetos, problemas de alinhamento entre os setores público e privado, necessidade de estudos científicos do turismo e pesquisa de mercado, pouca participação do setor privado no financiamento de projetos de turismo.

Palavras-chave: turismo; planejamento estratégico; planejamento do turismo.

\section{Abstract}

This article aims to identify which cities of the Santa Catarina Itineraries Regional prepared the strategic plan of the municipal tourism and evaluate the planning method applied on documents already completed. Analysis in the method was in two concepts: "strategic planning" according to the author Kotler (1998) and "tourism planning" Barretto (2005). The

\footnotetext{
${ }^{1}$ Pós-Graduação em Turismo: Consultoria Planejamento e Marketing - UNIVALI. Bacharel em Turismo e Hotelaria - UNIVALI. E-mail: planejatur@hotmail.com.

${ }^{2}$ Graduação em Turismo pela Universidade Federal do Paraná, Especialização em Administração Hoteleira pela UFES/SENAC, Planejamento Estratégico do Turismo pela ECA/USP e mestrado em Turismo e Hotelaria pela Universidade do Vale do Itajaí. Desde 1998 é professora titular da Universidade do Vale do Itajaí. E-mail: tomasulo@univali.br.
} 
methodology for the development of this study was research descriptive, qualitative and quantitative. The procedures were bibliographic, documentary research. The questionnaire was the instrument data collection. The results demonstrated that the strategic planning of tourism needs to improve in state. The main results obtained was: dependence on federal and state resources for plans and projects, problems in alignment between public sector and private, need more scientific studies of tourism and market research, little private sector participation in financing of tourism projects.

Keywords: tourism; strategic planning; tourism planning.

\section{Resumen}

Este artículo tiene como objetivo identificar las ciudades de el Santa Itinerarios Regional Catarina redactó el plan estratégico del turismo municipal y evaluar el método de planificación aplicada a los documentos ya terminados. El análisis se investigó la existencia de dos conceptos: la "planificación estratégica", según el autor Kotler (1998) y "la planificación del turismo" Barretto (2005). La metodología para el desarrollo de este estudio fue la investigación descriptiva, cualitativa y cuantitativa. Los procedimientos fueron bibliográfico, documental, el cuestionario fue instrumento de recolección de datos. Los resultados muestran que la planificación el turismo de las necesidades para mejorar en el estado. Los principales resultados, revelaron: la dependencia de recursos federales y estatales para los planes y proyectos, los problemas de alineación entre los sectores público y privado, necesitamos más estudios científicos del turismo y la investigación de mercado, poca participación del sector privado en la financiación de proyectos de turismo.

Palabras clave: turismo; planificación estratégica; turismo de planificación.

\section{Introdução}

O turismo de Santa Catarina permanece em destaque no cenário turístico nacional de 2006 até 2010, ficando entre o "Melhor Estado" no "Prêmio Viagem e Turismo", segundo os leitores da Revista Vigem e Turismo, uma das principais revistas de turismo do país. O trabalho das políticas públicas e do marketing institucional vem atraindo ano após anos mais turistas para região sul do país. Desta forma, preocupar-se com o crescimento sustentável do setor é determinante para o planejamento das localidades, buscando qualidade de vida para os moradores locais e para os turistas.

A competitividade mundial do setor turístico o diferencia dos demais setores econômicos, pois são inúmeras as variáveis que influenciam a escolha do turista para uma determinada 
cidade, tais como clima, segurança, fatores econômicos, culturais, etc. A instabilidade destas variáveis torna o planejamento estratégico, especificamente, um instrumento de vantagem competitiva, auxiliando gestores públicos e privados no processo de tomada de decisão para o desenvolvimento do turismo. Segundo Holanda (1974, p. 36), planejamento estratégico pode ser definido "como a aplicação sistemática do conhecimento humano para prever e avaliar cursos de ação alternativos com vistas à tomada de decisões adequadas e racionais, que sirvam de base para a ação futura".

Este artigo pretende contribuir para o estudo científico do turismo, pois, segundo Rejowsky (1998), é por meio da investigação científica que se deixará da fase de improvisação e de repetitividade e se passará à fase de aplicação e utilização desses estudos. A autora também apresenta a necessidade de divulgar a aplicabilidade e a pertinência dos resultados de pesquisa, mostrando os benefícios desta e da parceria pesquisador/empresário para o desenvolvimento e planejamento estratégico do turismo no Brasil.

Atualmente, no Estado de Santa Catarina, o documento de referência para o planejamento do turismo está consolidado no Plano Estadual da Cultura, do Turismo e do Desporto do Estado de Santa Catarina (PDIL) sendo este um documento que apresenta diagnóstico e diretrizes para o estado nas três áreas, ou seja, cultura, esporte e turismo. No entanto não apresenta de forma mais detalhada e específica de como cada município deveria agir, para chegar a atingir metas e objetivos de um planejamento central de turismo em Santa Catarina.

Considerando a relevância do planejamento estratégico para as cidades turísticas, o presente artigo pesquisou as 10 regiões turísticas consideradas mais relevantes e estas com maior fluxo turístico no Estado de Santa Catarina, de acordo com Santa Catarina Turismo S/A SANTUR, com o intuito de saber quais os municípios do estado já possuem um Plano Estratégico Municipal de Turismo e, dos planos identificados, pretende-se fazer uma avaliação qualitativa destes documentos. Assim, de cada região foi indicado um município para ser estudado pela pesquisa. Foram definidas, então, as regiões: Grande Florianópolis Florianópolis, Costa Verde Mar - Balneário Camboriú, Vale Europeu Blumenau, Caminho dos Príncipes - Joinville, Encantos do Sul - Laguna, Caminho dos Cânions - Araranguá, Caminhos da Fronteira - Dionísio Cerqueira, Serra Catarinense - Lages, Vale do Contestado Fraiburgo e Grande Oeste - Chapecó. 
A consequência da ausência de estudos do turismo e de planejamento turístico é o crescimento desordenado do setor, causando, muitas vezes, sérios problemas, tais como a degradação do meio ambiente, distorção de valores culturais e sociais, exploração imobiliária inadequada, inflação, aumento da marginalidade, prostituição, etc. Desta forma, os resultados desta pesquisa sobre o planejamento estratégico turístico é uma oportunidade para avaliar como os municípios estão planejando e desenvolvendo a atividade turística.

\section{Fundamentação Teórica}

\subsection{Políticas e planejamento turístico}

O crescimento do turismo no Brasil e no Estado de Santa Catarina requer um processo de planejamento eficaz, possibilitando que as cidades turísticas possam ter condições favoráveis de infraestrutura básica e turística e o uso moderado do meio ambiente.

O ordenamento da atividade turística garante o desenvolvimento das cidades turísticas de uma maneira sustentável, acarretando benefícios para todos os envolvidos. Conforme Barretto (2005), planejar significa equilibrar o atendimento às necessidades e propiciar o bem-estar de sujeitos sociais provenientes de outro lugar e, dentro de uma região receptora e seu meio ambiente, harmonizar também a relação dos turistas com a população nativa. Implica recompensar a comunidade que divide seu espaço com os turistas, financiando, com dinheiro proveniente do turismo, obras públicas requeridas para melhorar seu índice de desenvolvimento humano.

As políticas púbicas do turismo estabelecem diretrizes para o crescimento ordenado do setor, tais direcionamentos abrangem inúmeros setores da sociedade: organização dos territórios, geração de emprego, proteção do meio ambiente, controle da inflação local, capacidade de carga, entre outros.

No Brasil, foi a partir da década de 1990 que o turismo sofreu ajustes nas estruturas públicas federais e estaduais, foi nesta época que se solidificaram e, com respaldo governamental, começaram a criar e implantar programas em seus territórios (MINISTÉRIO DO TURISMO, 2009). 
Nacionalmente, o turismo está fundamentado no Plano Nacional de Turismo elaborado pelo Ministério do Turismo, o qual afirma que "a multidisciplinaridade do setor, os impactos econômicos, sociais, ambientais, políticos e culturais gerados pelo turismo exigem um processo de planejamento e gestão que oriente, discipline e se constitua em um poderoso instrumento de aceleração do desenvolvimento nos níveis local, regional e nacional." (PNT, 2007 p. 29). Dentro deste contexto, todas as ações a serem desenvolvidas devem estar embasadas pelas diretrizes estabelecidas pelos governos federal e estadual, visando à promoção de um desenvolvimento adequado do setor.

Para isso, a Lei Geral do Turismo $\mathrm{n}^{\circ} 11.771$ de 2008 traz algumas diretrizes sobre planejamento nacional do turismo, como no Capítulo II DA POLÍTICA, DO PLANO E DO SISTEMA NACIONAL DE TURISMO - Subseção II, que estabelece em seu “Artigo 5: VI promover, descentralizar e regionalizar o turismo, estimulando Estados, Distrito Federal e Municípios a planejar, em seus territórios, as atividades turísticas de forma sustentável e segura, inclusive entre si, com o envolvimento da comunidade local."

Portanto a atividade turística catarinense segue as políticas do Ministério do Turismo e da Secretaria de Estado de Turismo, Cultura e Esporte. No estado a lei que ordena o planejamento é a no 13.792 de 18 de julho de 2006, que determina em seu Artigo $1^{\circ}$ :

Fica instituído o Plano Estadual da Cultura, do Turismo e do Desporto do Estado de Santa Catarina - PDIL, em conformidade com os objetivos estratégicos de governo defínidos no Plano Plurianual, visando estabelecer as políticas, as diretrizes e os programas para a cultura, o turismo e o desporto do Estado de Santa Catarina.

Esta mesma lei, em seu Art. $5^{\circ}$, estabelece que "os projetos deverão ser formatados segundo regulamentação da Lei n- 13.336, de 8 de março de 2005, que instituiu o Sistema Estadual de Incentivo à Cultura, ao Turismo e ao Esporte - SEITEC", na qual em seu Art. $1^{\circ}$ menciona que este Sistema tem como objetivo,

[...] estimular o financiamento de projetos culturais, turísticos e esportivos especialmente por parte de contribuintes do Imposto sobre Operações Relativas à Circulação de Mercadorias e sobre Prestação de Serviços de Transporte Interestadual e Intermunicipal e de Comunicação - ICMS, na 
forma e nos limites estabelecidos nesta Lei.

Os requerentes para os recursos estaduais estão descritos no Art. 2:

O SEITEC tem por objetivo prestar apoio financeiro e financiamento de projetos voltados à infra-estrutura necessária às práticas da Cultura, Turismo e Esporte, mediante a administração autônoma e gestão própria dos respectivos recursos, além de projetos específicos relativos a cada setor apresentados por agentes que se caracterizam como pessoas físicas ou jurídicas de direito privado, órgãos públicos de turismo, esporte e cultura das administrações municipal e estadual.

Conforme o Art. $3^{\circ}$, fica instituído, no âmbito do SEITEC, o Fundo Estadual de Incentivo à Cultura - (FUNCULTURAL); o Fundo Estadual de Incentivo ao Esporte (FUNDESPORTE).; e o Fundo Estadual de Incentivo ao Turismo - (FUNTURISMO), de natureza financeira, é constituído com recursos provenientes das seguintes fontes, segundo o Art. 50: "I - recursos oriundos do FUNDOSOCIAL; II - receitas decorrentes da aplicação de seus recursos; III - contribuições, doações, financiamentos e recursos oriundos de entidades públicas ou privadas, nacionais ou estrangeiras; e IV - outros recursos que lhe venham a ser destinados."

Diante disto, o Estado de Santa Catarina e os seus municípios têm a oportunidade de criar projetos financiados para o desenvolvimento do setor turístico. Esta condição no estado favorece o setor, que deve de maneira política e articulada tentar captar estes recursos e investir também no planejamento do turismo.

Ressalta-se, portanto, que a gestão do turismo precisa de um pensamento lógico, formalizado num plano estratégico, baseado em: diagnóstico, objetivos, ações e controles cautelosos para a não degradação dos atrativos culturais e ambientais. Conforme Goeldner et al. (2002), o turismo mal planejado e desenvolvido desordenadamente poderá criar problemas nas localidades turísticas, gerando conflitos entre as necessidades e desejos dos turistas e dos residentes locais. Além disso, o desenvolvimento inadequado ou aleatório podem danificar o meio ambiente matéria-prima do turismo.

Considerando este aspecto, deve-se avaliar que nos últimos anos houve um aumento da demanda turística de Santa Catarina, conforme divulgado pela SANTUR, na qual se pode 
perceber que o total de turistas (nacional e estrangeiro) no ano de 2007 foi 4.008 .152 (milhões), em 2008 correspondeu a 4.303.423 e, em 2009, a 4.354.612. Tal crescimento do turismo solicita dos municípios produtos turísticos de qualidade para oferecer aos turistas. Atualmente no estado existe uma escassez de cidades preparadas para atender aos visitantes, principalmente no que se refere a problemas de acesso, infraestrutura básica e de apoio (principalmente de saneamento) e de infraestrutura turística, não oferecendo serviços adequados, bem como grande parte dos equipamentos turísticos, muitas vezes, estão ultrapassados e desgastados. Para mudar esta realidade de maneira positiva, os municípios turísticos precisam realizar seu planejamento estratégico, priorizando seus maiores problemas e colocando em prática as ações correspondentes para desenvolver o setor turístico catarinense, oferecendo melhor qualidade do produto turístico.

\subsection{Plano e planejamento estratégico em Santa Catarina}

A evolução do turismo catarinense está sujeita ao planejamento e às ações estratégicas da gestão pública municipal, que de acordo com Cooper et al. (1993, p. 137), "o planejamento e o gerenciamento são a chave para a garantia que as destinações turísticas e os recursos existentes sejam mais eficazes no atendimento da demanda."

No Estado de Santa Catarina a atividade turística já está consolidada. No entanto a prática do planejamento turístico é inconsistente. O estado e o ministério do turismo exercem suas responsabilidades com a elaboração de leis, programas e ações para o processo de planejamento que, na esfera municipal, o planejamento ainda necessita de maior atenção e otimização.

Conforme o World Travel and Tourism Council (WTTC, 2009), o turismo em Santa Catarina está concentrado no espaço e no tempo. Os locais de veraneio costeiros atraem a grande massa de visitantes no verão. $\mathrm{O}$ crescimento excessivo sem planejamento apresentaria o risco de criar desequilíbrios ainda maiores, que resultariam em uma pressão indevida sobre os ambientes costeiros e urbanos e seus respectivos sistemas de transporte. O crescimento planejado, por sua vez, pode ajudar a assegurar que todas as comunidades locais partilhem os benefícios, com uma melhor distribuição dos fluxos turísticos pelas diferentes localidades existentes e com potencial, estimulando o desenvolvimento econômico rural e fomentando as pequenas empresas. 
O planejamento é uma ação utilizada por todos os mercados, no turismo a concorrência entre as destinações é constante, portanto planejar pode ser fator decisivo para o sucesso. De acordo com Woiler (1996), o planejamento num âmbito geral pode ser definido como o desenvolvimento de processos, técnicas e atitudes administrativas, as quais poderão resultar numa situação viável para avaliar as implicações futuras de decisões presentes em função dos objetivos empresariais que facilitarão a tomada de decisão no futuro, de modo mais rápido, coerente, eficiente e eficaz.

Para efetuar o planejamento adequado, o Ministério do Turismo indica a realização do planejamento estratégico "o desenvolvimento do turismo regional depende inteiramente do Plano Estratégico de Desenvolvimento Regional do Turismo, para ordenar, sistematizar e integrar as ações que determinarão benefícios futuros socioeconômicos e ambientais." (MINISTÉRIO DO TURISMO, 2008, p. 49).

As funções do plano estratégico são imprescindíveis para o turismo, indicando direcionamentos para a atividade. O plano fornece informações aos gestores para criarem estratégias, qualificarem seus produtos turísticos e, consequentemente, ser mais competitivo em relação aos outros destinos. Ainda, os secretários e os empresários de uma cidade turística podem utilizar os planos estratégicos para otimizarem os recursos e executarem controles, minimizando os possíveis problemas resultantes da atividade turística.

O plano estratégico pode nortear todo o processo de desenvolvimento ou reordenamento do turismo numa localidade, sendo uma atividade sistemática, assim, fica claro a importância do plano oferecendo objetivos comuns aos envolvidos e, quando bem planejado, benefícios a todos. Como descreve Thompson \& Strickland (2004, p. 33), o "plano estratégico é uma declaração que delineia a missão de uma organização e seu rumo futuro, suas metas de desempenho de curto prazo e de longo prazo e sua estratégia."

Atualmente, existe outro processo de planejamento no estado que está em fase de aprovação no legislativo, são os Planos Regionais de Turismo, tal ação faz parte do "Programa de Regionalização" do Ministério do Turismo, que propõe a estruturação, o ordenamento e a diversificação da oferta turística no país (MINISTÉRIO DO TURISMO, 2010). 
O PDIL e os Planos Regionais de Turismo do estado são documentos de referência para as prefeituras elaborarem seu plano estratégico de turismo. Também é de suma importância criar um plano estratégico com fundamentos científicos, que, segundo Barretto (2005), devem fazer parte a criatividade e a intuição, pois estes elementos são essenciais ao planejamento, pois, para a autora, basear-se somente na intuição ou criar a partir do nada são contrários ao planejamento científico.

Para Kotler (1998, p. 101), as etapas do planejamento estratégico são compostas dos seguintes itens:

a) Análise de Ambiente Externo: econômico-social, político-legal, tecnológico, demográfico, ecológico, cultural, forças da indústria e mercadológico-concorrencial;

b) Análise do Ambiente Interno: recursos naturais, recursos artificiais e temáticos, recursos patrimoniais e culturais, recursos disponíveis no local, estágio do ciclo de vida e competências essenciais;

c) Análise das Tendências, Oportunidades e Ameaças, Pontos Fortes e Fracos;

d) Definição das Estratégias, Objetivos, Posicionamento, Programas e Ações;

e) Acompanhamento, Controle e Revisão.

$\mathrm{Na}$ atividade turística não existe um modelo específico de planejamento. Portanto utilizar o planejamento estratégico, considerando as variáveis e o contexto do turismo é um método adequado. A instabilidade do setor turístico e suas constantes mudanças exigem dos gestores incontáveis soluções de problemas, sendo assim, a criação de estratégias é fundamental. Conforme Tavares (1991, p. 71), o planejamento estratégico funciona como um instrumento para tomada de decisões e suas principais funções são:

- Proporcionar maior interação entre a organização e seu meio ambiente;

- Determinar instâncias e dar coerência ao processo decisório;

- Definir a direção os objetivos e as linhas de ação mais oportuna e adequada;

- Viabilizar o desenvolvimento de modelos organizacionais mais adequados ás demandas ambientais;

- Coordenar e otimizar a alocação de recursos; 
- $\quad$ Estabelecer mecanismos de avaliação e controles voltados para a eficácia, a eficiência e a efetividade da organização.

Outra definição conceitual para a conclusão deste trabalho é entender o planejamento sobre o ponto de vista do turismo, no Quadro 1 estão detalhadas as etapas, a descrição e os documentos utilizados no planejamento turístico. O quadro foi utilizado para duas fases na elaboração deste artigo, a primeira na elaboração do questionário encaminhado para os secretários de turismo das cidades pesquisadas e a segunda na avaliação qualitativa dos planos. De acordo com Barretto (2005), o planejamento é a necessidade de adequação entre o fluxo turístico e o núcleo receptor. No quadro a autora descreve as etapas do planejamento:

\begin{tabular}{|c|c|c|}
\hline ETAPAS & DESCRIÇÃO & DOCUMENTO \\
\hline $\begin{array}{c}\text { ESCOLHA E } \\
\text { DELIMITAÇÃO }\end{array}$ & $\begin{array}{l}\text { Estudo dos fatores físicos (solo, clima, etc.); } \\
\text { Informações sócio-demográficas, administrativos, } \\
\text { custo de mão-de-obra local. } \\
\text { Informações sobre infraestrutura preexistente, (luz, } \\
\text { água, esgoto), sobre estágio de tecnologia, dos } \\
\text { transportes das dependências externas. }\end{array}$ & $\begin{array}{c}\text { Aerofotogramas } \\
\text { Climgramas } \\
\text { Maquetes } \\
\text { Relatório }\end{array}$ \\
\hline $\begin{array}{c}\text { ESTUDO } \\
\text { DIAGNÓSTICO }\end{array}$ & \begin{tabular}{|c|} 
Inventário da infra-estrutura turística \\
Estudo da economia da Região. \\
Estudos das leis e normas de Urbanização. \\
Estudos das leis ambientais. \\
Estudos das leis trabalhistas. \\
Estudo da evolução das correntes turísticas. \\
Estudo Socioeconômico dos turistas. (se houver) \\
Estudos de outras propostas concorrentes. \\
Inventário dos recursos humanos \\
\end{tabular} & $\begin{array}{l}\text { Relatório } \\
\text { Diagnostico }\end{array}$ \\
\hline $\begin{array}{c}\text { DEFINIÇÃO } \\
\text { DE OBJETIVOS METAS }\end{array}$ & $\begin{array}{l}\text { Estudo de variáveis intervenientes. Determinação } \\
\text { dos setores prioritários de intervenção. } \\
\text { Priorização de objetivos. } \\
\text { Determinação de Prazos. } \\
\text { Determinação de capacidade de atendimento em } \\
\text { instalações turísticas e infra-estrutura. }\end{array}$ & $\begin{array}{l}\text { Proposta Preliminar ou } \\
\text { Anteprojeto. }\end{array}$ \\
\hline $\begin{array}{l}\text { ESCOLHAS DE } \\
\text { ALTERNATIVAS DE } \\
\text { INTERVENÇÃO }\end{array}$ & $\begin{array}{l}\text { Estudo de viabilidade econômica. } \\
\text { Estudo de relação custo/benefício. } \\
\text { Análise das repercussões sociais. }\end{array}$ & Projeto \\
\hline IMPLEMENTAÇÃO & $\begin{array}{c}\text { Zoneamento. } \\
\text { Hierarquização. } \\
\text { Construções de equipamentos e acessos. } \\
\text { Adequação dos equipamentos preexistentes. } \\
\text { Adequação da legislação. }\end{array}$ & $\begin{array}{l}\text { Cronogramas } \\
\text { Plantas e } \\
\text { Planilhas. }\end{array}$ \\
\hline EXECUÇÃO, & Comercialização. & Relatório \\
\hline
\end{tabular}




\begin{tabular}{c|c|c}
\hline CONTROLE & Verificação da concorrência entre o planejado e & \\
E AVALIAÇÃO & executado. & \\
\hline
\end{tabular}

Quadro 1 - Etapas do planejamento turístico

Fonte: Barretto (2005. p. 71).

Os destinos turísticos de Santa Catarina, se planejados estrategicamente, alcançariam um diferencial competitivo, adequando da melhor maneira seu produto turístico com as mudanças do mercado mundial e necessidades dos turistas. Como descreve Thompson Jr. \& Strickland (2004), as estratégias das empresas correspondem a como satisfazer os clientes e estar à frente da concorrência e responder às condições variáveis do mercado.

O planejamento estratégico foi o instrumento selecionado para o tema da atual pesquisa, mas não é a única forma de planejar, administrar e praticar a gestão do turismo. Porém, considerando sua abrangência, torna-se um processo extremamente facilitador no desenvolvimento do turismo sustentável de uma localidade. Com uma abordagem global e sistêmica para gerir o turismo, o plano estratégico de turismo municipal serve para orientar o desenvolvimento do turismo. $\mathrm{O}$ documento deve ser produzido com a metodologia adequada e com a participação de todos os envolvidos: órgãos públicos, entidades de classe do setor comunidade e turista.

\section{Metodologia}

Para o delineamento da pesquisa, selecionou-se a pesquisa descritiva que, segundo Rudio (1986), é aquela em que o pesquisador procura conhecer e interpretar a realidade, sem nela interferir para modificá-la. A pesquisa descritiva está interessada em descobrir e observar fenômenos, buscando descrevê-los, classificá-los e interpretá-los. O objetivo geral inicial desta investigação era identificar quais são os municípios do Estado de Santa Catarina que já elaboraram o seu Plano Estratégico Municipal de Turismo e dos planos identificados e finalizados, descrever quais são as metas que foram alcançadas e quais metas deverão ser atingidas. Entretanto o resultado da pesquisa não obteve dados suficientes para atingir seu propósito original, pois das dez cidades pesquisadas apenas duas cidades enviaram seus 
planos. Desta forma, optou-se por uma avaliação metodológica do planejamento dos planos estratégicos de turismo recebidos.

A pesquisa bibliográfica foi utilizada para a construção da fundamentação teórica, questionário e avaliação dos planos estratégicos de turismo que, segundo Gil (2002), a pesquisa bibliográfica é desenvolvida com base em material já elaborado, constituído principalmente de livros e artigos científicos.

Os dados do planejamento do turismo de Santa Catarina foram pesquisados em documentos oficiais do governo, caracterizando também como pesquisa documental, que conforme o autor citado são estudos feitos em materiais que não receberam ainda um tratamento analítico, ou que ainda podem ser reelaborados de acordo com os objetos da pesquisa.

Selecionou-se a pesquisa quantitativa para a elaboração e a aplicação do questionário, fazendo o levantamento de dados do planejamento estratégico nas secretarias de turismo. Conforme Oliveira (2001), o método quantitativo significa quantificar opiniões, dados, nas formas de coleta de informações, assim como com o emprego de recursos e técnicas estatísticas.

Quanto à avaliação metodológica dos planos de turismo, pode ser caracterizada como pesquisa qualitativa. Conforme Neves (1996), a pesquisa qualitativa são técnicas interpretativas que tendem a descrever e a decodificar os componentes de um sistema complexo de significados.

A amostra da pesquisa é não aleatória que, conforme Barbetta (2001, p. 55), “em geral, as técnicas de amostragem não aleatórias procuram gerar amostra, que de alguma forma, representem razoavelmente bem a população de onde foram extraídas". Assim, o turismo de Santa Catarina divide-se em 10 roteiros turísticos regionais pelo órgão oficial do governo, a SANTUR (2010) e, para este estudo, foi selecionado um município de cada roteiro turístico pertencente às regiões turísticas do estado.

A pesquisa do Estudo dos Planos Estratégicos Municipais de Turismo dos Roteiros Turísticos Regionais de Santa Catarina foi realizada de julho a novembro de 2010. Os municípios e Roteiros Turísticos Regionais de Santa Catarina, respectivamente, foram: Grande Florianópolis - Florianópolis, Costa Verde Mar - Balneário Comburiu, Vale Europeu Blumenau, Caminho dos Príncipes - Joinville, Encantos do Sul - Laguna, Caminho dos 
Cânions - Araranguá, Caminhos da Fronteira - Dionísio Cerqueira, Serra Catarinense - Lages, Vale do Contestado - Fraiburgo e Grande Oeste - Chapecó.

Na primeira etapa da pesquisa, o instrumento de coleta de dados pré-estabelecido foi o questionário, elaborado com perguntas semiabertas, contendo os seguintes temas: Organização do turismo no município; Impactos positivos do turismo mais evidentes no município; Impactos negativos do turismo mais evidentes no município; Técnica ou processo utilizado para planejar o turismo; Legislações utilizadas no planejamento turístico do município; Parceiros na administração municipal do turismo; Captação de recursos e órgãos financiadores. Foi encaminhado por e-mail um questionário para cada secretaria de turismo das cidades pesquisadas para que os gestores ou os secretários de turismo respondessem. Por meio de contato telefônico, solicitou-se a colaboração das secretarias de turismo para responderem a pesquisa, para posterior tabulação e análise.

$\mathrm{Na}$ segunda etapa, elaborou-se uma avaliação metodológica dos planos estratégicos de turismo recebidos das secretarias de turismo, os documentos foram solicitados ao final do questionário para fase complementar da pesquisa. Os planos recebidos foram nomeados de Plano de Turismo - A e Plano de Turismo - B, para resguardar eticamente o trabalho das secretarias.

A avaliação dos planos foi executada da seguinte forma. Foram adotados dois conceitos, um sobre as etapas do "planejamento estratégico" do autor Kotler (1998), com as variáveis; Análise de Ambiente Externo, Análise do Ambiente Interno, Definição das EstratégiasObjetivos, Posicionamento - Programas e Ações; Acompanhamento, Controle e Revisão. O segundo conceito foi as etapas do "planejamento do turismo" da autora Barreto (2005), tendo as variáveis a Escolha e a Delimitação do estudo, Diagnóstico, Definição de objetivos metas, Escolhas de alternativas de intervenção, Implementação, Execução - Controle e avaliação.

Para realizar a análise dos planos, Plano de Turismo - A e Plano de Turismo - B, verificou-se a existência das variáveis citadas nos documentos, classificando-as como: Atende (A) 2 pontos, Atende Parcialmente (AP) 1 ponto, Não Atende (NA) 0 ponto e Inexistente (I). Após esta revisão, é feito o somatório da pontuação das variáveis veja no (Quadro 3). Por fim, foi estabelecida uma escala de classificação dos pontos obtidos sendo: 
- De 0 - 8 (Inadequado), concluindo que o plano estratégico - PE de turismo é inadequado e deve ser revisto, não apresentando coincidentes com as variáveis de Kotler e Barretto.

- De 9 - 16 (Parcialmente adequado), concluindo que o PE de turismo é parcialmente adequado e foi elaborado com os conceitos do turismo e do plano estratégico, referenciados na metodologia, porém o documento apresenta itens que devem ser corrigido para melhor aproveitamento do trabalho elaborado.

- De 17 - 24 (Adequado), significando que o PE de turismo é adequado e está metodologicamente correto de acordo com os conceitos recomendados por Kotler e Barretto.

Quanto às limitações da pesquisa, pôde-se observar a dificuldade de comunicação das secretarias de turismo, tendo que reencaminhar a solicitação da resposta da pesquisa, pois acusavam o não recebimento do documento ou problemas com e-mails. Também a escassez dos planos estratégicos de turismo na população pesquisada restringiu os resultados do trabalho, sendo apenas duas amostras para avaliação metodológica de planejamento.

\section{Análises dos Resultados}

Neste item será apresentada a análise dos resultados obtidos por meio do questionário aplicado nas secretarias de turismo dos municípios que pertencem aos Roteiros Turísticos Regionais de Santa Catarina.

Notou-se no Gráfico 1 que as ações e os documentos administrativos são utilizados pela maioria das secretarias pesquisadas, facilitando a gestão das secretarias. No entanto, a alternativa "Estudos" foi citada por apenas 30\% dos entrevistados, fator este que deve ser observado pelas secretarias, uma vez que o planejamento do turismo procede do levantamento de informações do município, tais como: inventário, diagnóstico, estudos econômicos do turismo, pesquisa de satisfação dos turistas, etc. 


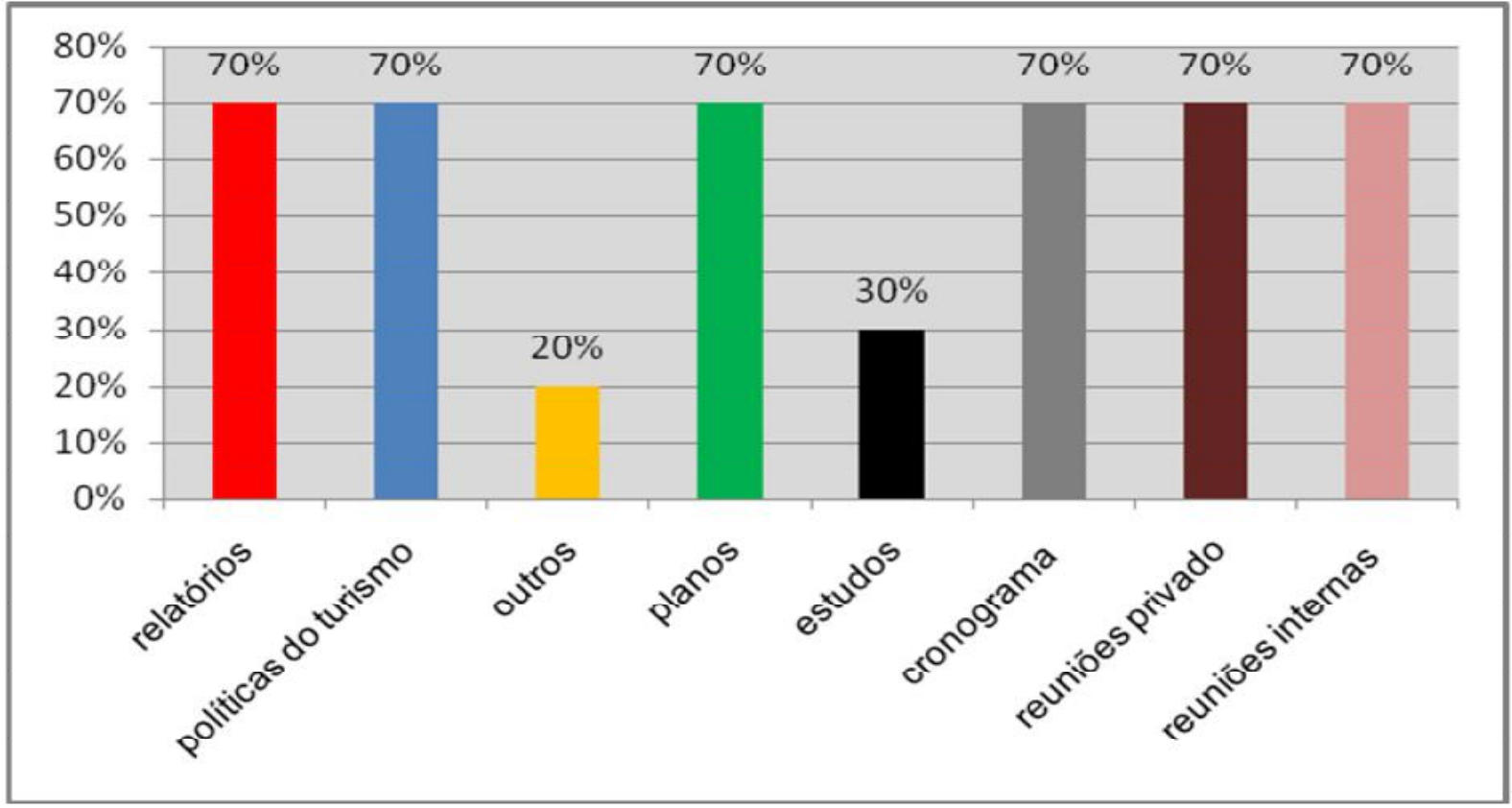

Gráfico 1 - Organização do turismo no município

Fonte: Pesquisa aplicada por Severino (Jul./2010).

O tema "Impactos do Turismo" foi abordado nos gráficos 2 e 3 da pesquisa. De acordo com Ruschmann (1997), os impactos do turismo referem-se à gama de modificações ou à sequência de eventos produzidos pelo processo do desenvolvimento turístico nas localidades receptoras.

Observou-se que 90\% dos entrevistados indicaram impactos econômicos positivos do turismo. A atividade turística gera movimentação econômica com a inserção de dinheiro deixado por turistas na economia local, além da geração de emprego e renda nos locais turísticos. 


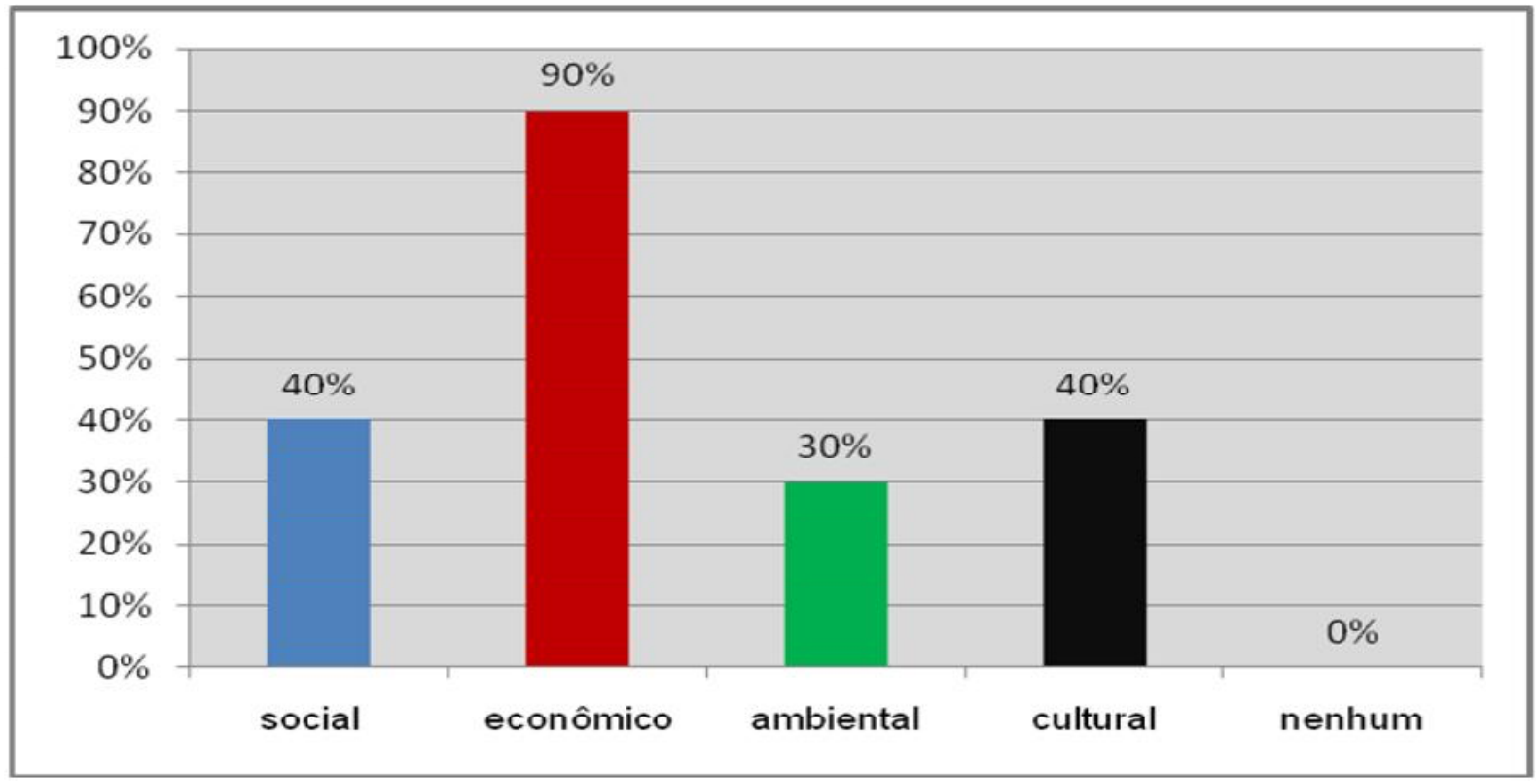

Gráfico 2 - Impactos positivos do turismo mais evidentes no município Fonte: Pesquisa aplicada por Severino (Jul./2010).

No Gráfico 3 os impactos negativos do turismo são menos indicados, pôde-se verificar a porcentagem máxima de 30\% para cada área apresentada. A metade dos municípios, 50\%, assinalou a opção "Nenhum", tal fato pode ser ocasionado pela falta de pesquisas a respeito dos impactos negativos do turismo nas cidades turísticas de Santa Catarina.

Um dos aspectos mencionados, caracterizado como problema ambiental causado pelo turismo, foi apresentado por um dos respondentes: "Durante a temporada de verão a capacidade de carga é levada ao limite" e ocorrência de "Invasões e construções em áreas de preservação". Diante disto, verificamos que os resultados estão de acordo com Cooper et al. (1993, p. 183), "como o turista têm que visitar o local de produção para que possam consumir o produto, é inevitável que a atividade turística esteja associada a impactos ambientais."

O processo do desenvolvimento do turismo está vinculado a uma série de cuidados para as localidades. O planejamento estratégico do turismo, nestas cidades, pode organizar os impactos da atividade turística: maximizando os benefícios e minimizando os problemas. 


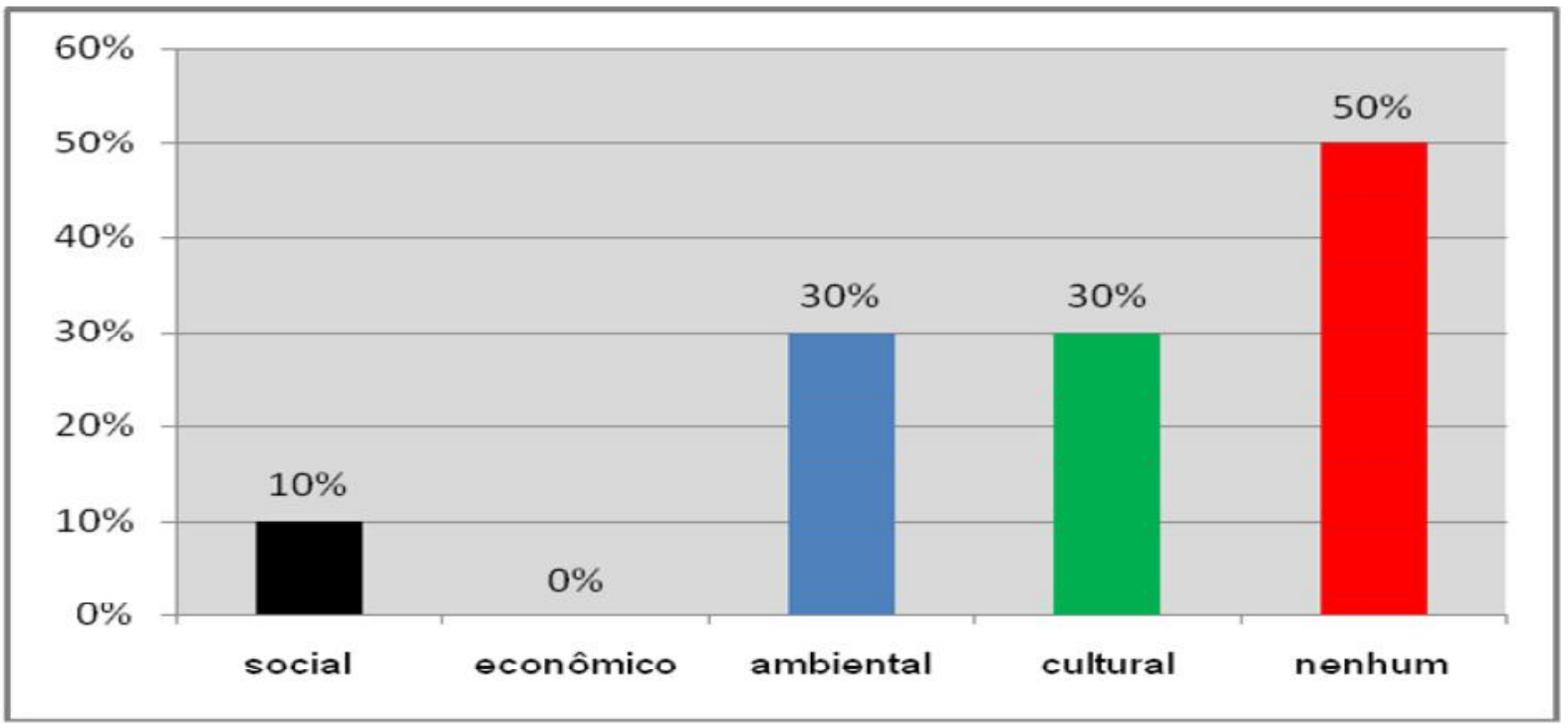

Gráfico 3 - Impactos negativos do turismo mais evidentes no município Fonte: Pesquisa aplicada por Severino (Jul./2010).

Conforme os dados obtidos no Gráfico 4, pôde-se observar que todas as etapas citadas por Barretto (2005) e Kotler (2008) do planejamento foram mencionadas pelos gestores municipais pesquisados. Nota-se também uma significativa variação dos percentuais para cada fase do item especificado, deixando claro que o Plano Estratégico na maioria das secretarias de turismo estudadas tem, principalmente, cinco fases (considerando os valores de $60 \%$ e $70 \%$ ) orçamento, programas, ações, estratégias, implementação de ações e objetivos.

Verificaram-se também, os itens do planejamento menos mencionados: análise situacional, apenas $40 \%$, controle $20 \%$ e implementação das ações $20 \%$.

Apesar de as cidades apontarem na pesquisa as etapas do planejamento e somente duas cidades cederem seus planos de turismo para análise, observou-se que nenhuma das dez cidades pesquisadas possui um planejamento estratégico de turismo completo, isto é, fazendo uma abordagem que se pressupõe como a ideal, focando tanto no turismo como no planejamento estratégico, conforme os conceitos dos autores referenciados nesta pesquisa. 


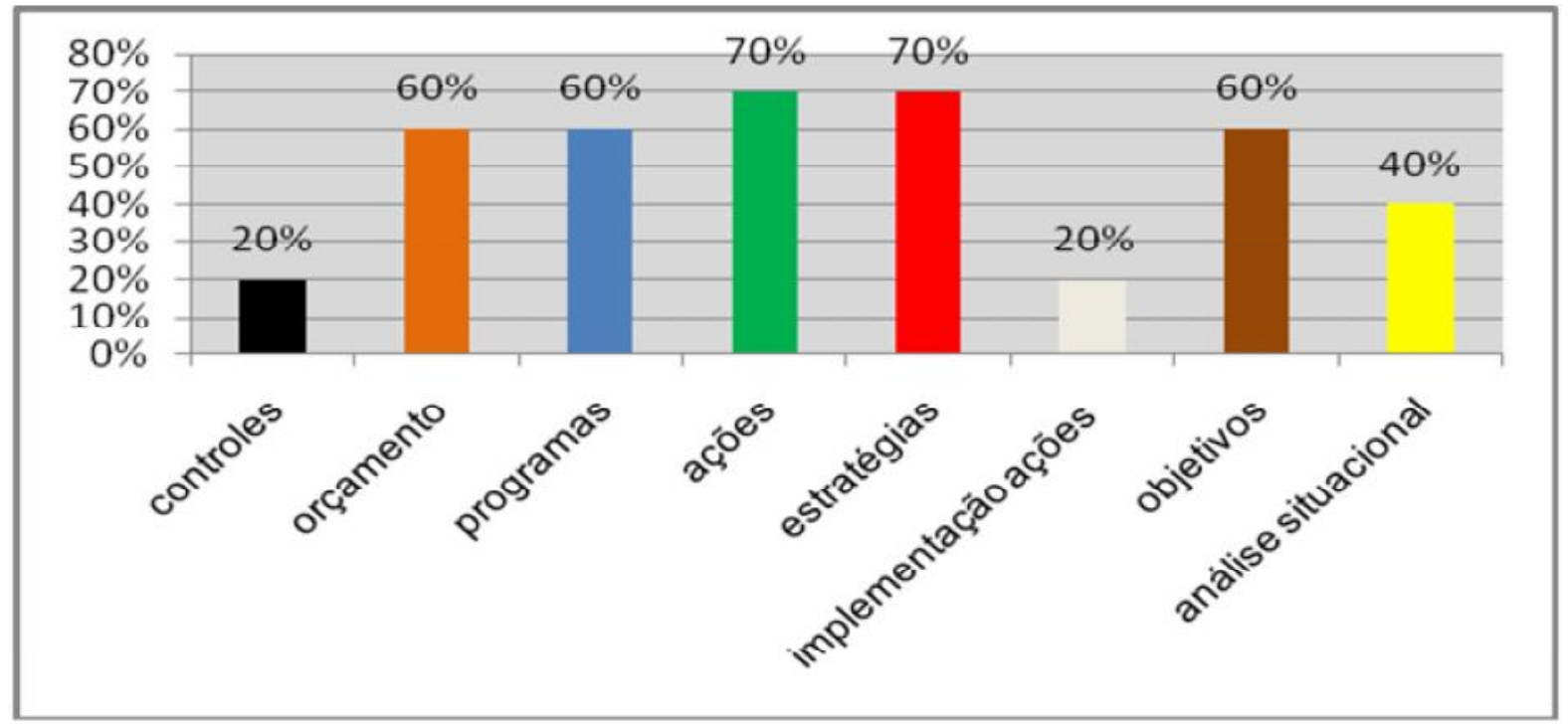

Gráfico 4 - Técnica ou processo utilizado para planejar o turismo Fonte: Pesquisa aplicada por Severino (Jul./2010).

As políticas públicas, por intermédio das leis, regularizam e norteiam a atividade turística. Observou-se que mais de $60 \%$ dos municípios possuem leis que auxiliam maior organização e monitoramento do desenvolvimento turístico, conforme informado pelos respondentes.

As legislações apontadas nesta pesquisa são fatores positivos e facilitadores para elaboração do planejamento estratégico do turismo nestas localidades, pois como afirma o Ministério do Turismo (2009), o desenvolvimento econômico positivo, cultural, ambiental e político do Brasil depende de uma política pública responsável, que se articule com as políticas do setor privado ou institucionais, ou seja, de grupos também interessados no desenvolvimento sustentável e ético do país. 


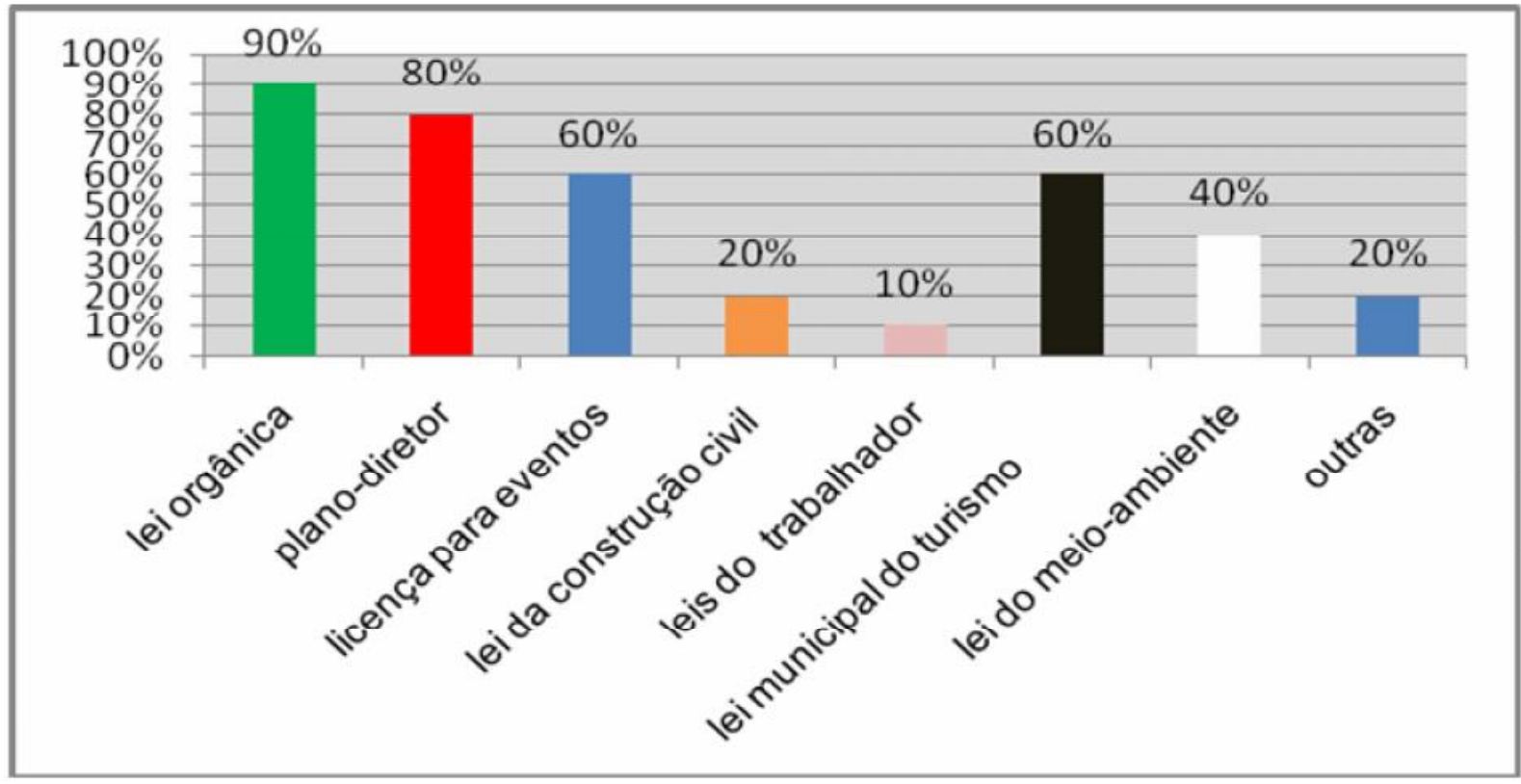

Gráfico 5 - Legislações utilizadas no planejamento turístico do município Fonte: Pesquisa aplicada por Severino (Jul./2010).

No Gráfico 6, o item participação dos moradores no turismo local atingiu 50\%, a porcentagem confirma que o planejamento participativo e integrado pode ser uma realidade nos destinos turísticos.

Ainda no Estado de Santa Catarina está sendo executada a política de regionalização alinhada com o Ministério do Turismo. Porém apenas 40\% dos pesquisados apontaram parcerias com outros municípios.

Observou-se também que somente $20 \%$ das cidades têm como parceiros agentes financiadores. Percebe-se, então, que esta condição atual precisa ser revista, pois o financiamento de planos e projetos é essencial para do desenvolvimento do turismo.

$\mathrm{Na}$ administração do turismo municipal, o setor privado participa integralmente, notou-se que $100 \%$ das prefeituras apontaram que os empresários locais têm "interesse" na atividade. No entanto, quando se trata de patrocinar projetos e planos, a realidade é bem diferente, conforme demonstrado no Gráfico 7. 


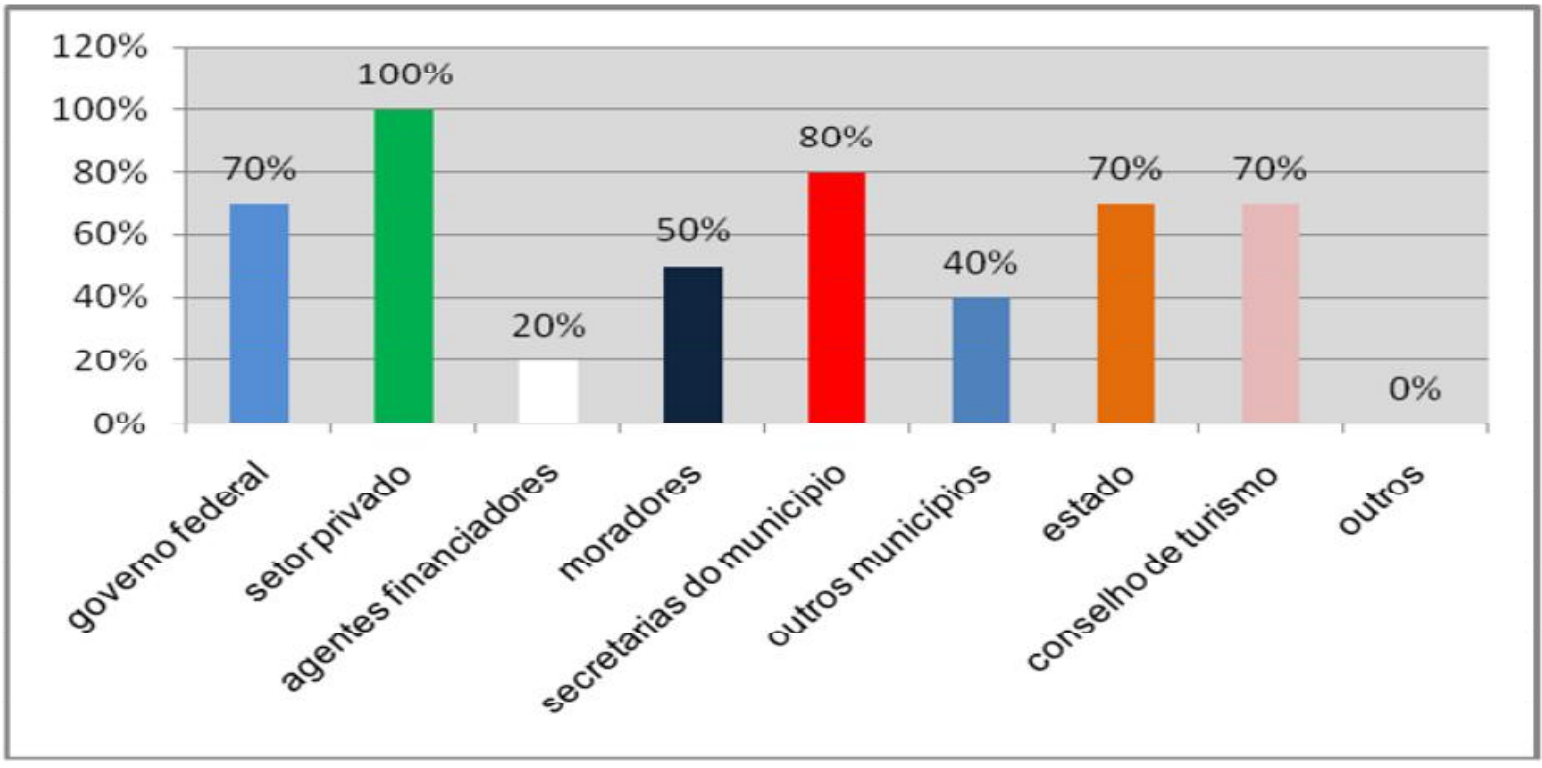

Gráfico 6 - Parceiros na administração municipal do turismo

Fonte: Pesquisa aplicada por Severino (Julho/2010).

Através do Gráfico 7, constatou-se a dependência de recursos que as secretarias municipais de turismo têm com o governo federal e estadual para fomentar o turismo, ao observar que $80 \%$ dos pesquisados citam o Ministério e $60 \%$ a Secretaria Estadual, como provedores de recursos, considerando que era uma questão de múltipla escolha.

Outro fator a ser discutido são as parcerias público-privadas, pois caracterizam como uma nova forma para desenvolvimento do turismo local. Verificou-se que apenas $20 \%$ dos gestores apontaram as empresas privadas como financiadoras de projetos da atividade turística municipal.

A captação de recursos de outros ministérios: cultura, cidades e agricultura abaixo indicados, evidencia a interdependência do turismo com os demais setores da sociedade. Sendo assim, pôde-se concluir que a atividade turística pode ser financiada por várias fontes, indicando novos caminhos para captação de recursos. 


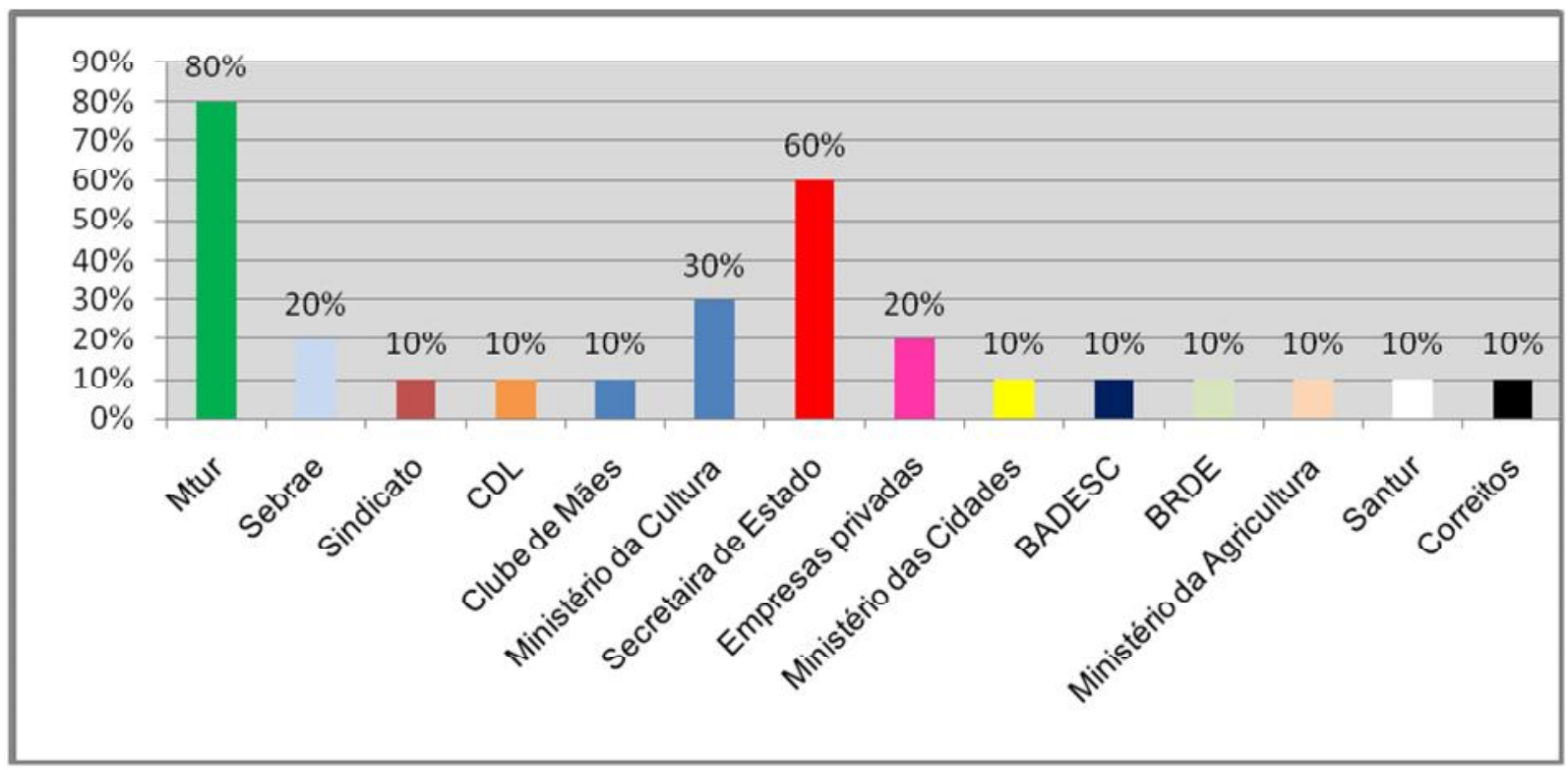

Gráfico 7 - Captação de recursos e órgãos financiadores

Fonte: Pesquisa aplicada por Severino (Julho/2010).

Percebeu-se que as secretarias de turismo já praticam de maneira informal, mas ainda não em sua totalidade o planejamento, aplicando cinco fases do processo: orçamento, programas, ações, estratégias, implementação de ações e objetivos. Outro fator constatado é que $60 \%$ dos municípios possuem leis que auxiliam maior organização e monitoramento do desenvolvimento turístico, fato fundamental para o crescimento do turismo sustentável. Nos impactos positivos do turismo, $90 \%$ das cidades pesquisadas apontam impactos econômicos benéficos para as cidades revelação.

Os fatores conflitantes são a insuficiência de estudos sobre o turismo, escassez de levantamento de informações do setor turístico, a degradação ambiental causada pelo turismo, poucos parceiros e agentes financiadores privados para planos e projetos, dependência dos governos federal e estadual para captação de recursos.

Mas a ausência de planos estratégicos do turismo no estado é o fator de maior relevância para este estudo, pois das 10 (dez) cidades pesquisadas, 8 (oito) destas ainda não possuem um documento que norteia a atividade turística de sua cidade, considerando o fato de se classificarem cidades turísticas importantes de Santa Catarina, destaques dos Roteiros 
Turísticos Regionais e, muitas vezes, consideradas exemplo para outras que desejam desenvolver o turismo.

\subsection{Análise dos planos}

Para complementação e interpretação dos dados da pesquisa dos Planos Estratégicos dos Roteiros Turístico Regionais de Santa Catarina, solicitou-se no final do questionário documentos relacionados com a pesquisa datados de 2003 a 2010. Foram recebidos dois planos estratégicos de turismo, que a seguir terão uma avaliação do método de planejamento empregado nos documentos. Os planos serão chamados nesta análise de "Plano de TurismoA" que está sendo elaborado e em fase aprovação, e "Plano de Turismo-B".

O plano estratégico de turismo para ser desenvolvido de maneira adequada tem como características principais: a necessidade da participação de todos os envolvidos com o turismo local e a aplicação de uma metodologia científica. Diante disto, para avaliar de maneira racional os planos, Plano de Turismo - A e Plano de Turismo - B, adotamos dois conceitos científicos, com metodologias apropriadas para executar um plano estratégico de turismo: o primeiro "planejamento estratégico" do autor Kotler (1998), com as variáveis: Análise de Ambiente Externo, Análise do Ambiente Interno, Definição das Estratégias Objetivos Posicionamento - Programas e Ações; Acompanhamento, Controle e Revisão. O segundo, de Barretto (2005), com as variáveis: Escolha e delimitação do estudo, Diagnóstico, Definição de objetivos metas, Escolhas de alternativas de intervenção, Implementação, Execução - Controle e avaliação.

No Quadro 3 elaborou-se uma avaliação qualitativa dos planos estratégicos de dois municípios (A e B) sendo considerada nos documentos a existência de cada variável de Kotler e Barretto, estabelecendo critérios para análise como: Atende (A) 2 pontos, Atende Parcialmente (AP) 1 ponto, Não Atende (NA) 0 pontos e Inexistente (I). Estabeleceu-se como um plano adequado o total de 24 pontos. 


\section{FATORES DE AVALIAÇÃO}

Planejamento Turístico - Barreto (2005)

\section{Planos}

\begin{tabular}{|c|c|}
\hline \multicolumn{2}{|c|}{ Planos } \\
\hline $\begin{array}{l}\text { Plano de } \\
\text { Turismo - }\end{array}$ & $\begin{array}{l}\text { Plano de } \\
\text { Turismo - B }\end{array}$ \\
\hline AP -1 & AP -1 \\
\hline AP -1 & AP -1 \\
\hline AP -1 & AP -1 \\
\hline I & AP -1 \\
\hline I & AP -1 \\
\hline I & I \\
\hline \multicolumn{2}{|c|}{ Planos } \\
\hline $\begin{array}{l}\text { Plano de } \\
\text { Turismo - } \\
\text { A }\end{array}$ & $\begin{array}{l}\text { Plano de } \\
\text { Turismo - B }\end{array}$ \\
\hline AP - 1 & AP - 1 \\
\hline A - 2 & AP - 1 \\
\hline AP - 1 & AP - 1 \\
\hline A - 2 & AP - 1 \\
\hline I & AP - 1 \\
\hline I & I \\
\hline 09 & 10 \\
\hline
\end{tabular}

1- ESCOLHA E DELIMITAÇÃO: Estudo dos fatores físicos (solo, clima, etc); Informações sociodemográfcios, administrativos, custo de mão-de-obra local. Informações sobre infra-estrutura preexistente, (luz, água, esgoto), sobre estágio de tecnologia, dos transportes das dependências externas.

2-ESTUDO DIAGNÓSTICO: Inventário da infra-estrutura turística; Estudo da economia da Região; Estudos das leis e normas de Urbanização; Estudos das leis ambientais; Estudos das leis trabalhistas; Estudo da evolução das correntes turísticas; Estudo Socioeconômico dos turistas (se houver); Estudos de outras propostas concorrentes; Inventário dos recursos humanos.

3-DEFINIÇÃO DE OBJEITIVOS METAS: Estudo variáveis intervenientes; Determinação dos setores prioritários de intervenção; Priorização de objetivos; Determinação de Prazos; Determinação de capacidade de atendimento em instalações turísticas e infra-estrutura.

4-ALTERNATIVAS DE INTERVENÇÃO: Estudo de viabilidade econômica; Estudo de relação custo/benefício; Análise das repercussões sociais.

5-IMPLEMENTAÇÃO: Zoneamento; Hierarquização; Construções de equipamentos e acessos; Adequação dos equipamentos preexistentes; Adequação da legislação.

6-EXECUÇÃO, CONTROLE E AVALIAÇÃO: Comercialização. Verificação da concorrência entre o planejado e executado.

FATORES DE AVALIAÇÃO

Planejamento Estratégico - Kotler (1998)

\begin{tabular}{l|c|c} 
& $\begin{array}{c}\text { Turismo - } \\
\text { A }\end{array}$ & Turismo - B \\
\hline 7 - Análise de Ambiente Externo & AP - 1 & AP - 1 \\
\hline 8 - Análise do Ambiente Interno & A - 2 & AP - 1 \\
\hline 9 - Análise das Tendências & AP - 1 & AP - 1 \\
\hline 10 - Definição das Estratégias-Objetivos & A - 2 & AP - 1 \\
\hline 11 - Posicionamento, Programas e Ações & I & AP - 1 \\
\hline 12 - Acompanhamento, Controle e Revisão & I & I \\
\hline TOTAL & $\mathbf{0 9}$ & $\mathbf{1 0}$ \\
\hline
\end{tabular}

Quadro 2 - Avaliação qualitativa dos planos estratégicos segundo Kotler (1998) e Barreto (2005)

Fonte: Pesquisa aplicada por Severino (Jul./ 2010). 
Para a classificação, temos como escala as pontuações totais obtidas:

- De $0-8$ - concluindo que o plano estratégico - PE de turismo não atende aos critérios estabelecidos pelas metodologias e deve ser revisto, não apresentando as variáveis de Kotler e Barretto.

- De 9 - 16 - concluindo que o PE de turismo parcialmente atende aos critérios estabelecidos e foi elaborado com os conceitos do turismo e do plano estratégico, referenciados na metodologia, porém o documento apresenta itens que devem ser corrigidos para melhor aproveitamento do trabalho elaborado.

- De 17 - 24 - significando que o PE de turismo está metodologicamente correto, de acordo com os conceitos recomendados por Kotler e Barretto.

O plano estratégico - Plano de Turismo - A foi classificado com 09 pontos, avaliado na escala de pontuação parcialmente atende aos critérios estabelecidos. Apesar de o documento não estar completo, ainda na fase de elaboração, isto é, contendo apenas diagnóstico e ações estratégicas, o trabalho apresentou aspectos do planejamento turístico e planejamento estratégico. No entanto, quando comparado aos conceitos de Kotler e Barreto não atendiam totalmente a cada variável avaliada, alguns fatores não foram considerados, um exemplo: na Etapa - 2 - Estudo Diagnóstico de Barretto - Quadro 2, o plano não continha estudos das leis ambientais e os estudos das leis trabalhistas.

Realizado pela secretaria de turismo municipal em junho de 2010, o Plano de Turismo - A fez o diagnóstico da atividade turística de maneira adequada através da metodologia Strengths (Forças), Weaknesses (Fraquezas), Opportunities (Oportunidades), Threats (Ameaças) SWOT. Quanto às ações estratégicas, avaliou-se como apropriadas para solucionar os problemas levantados no diagnóstico. Os principais pontos apresentados foram: parcerias público-privadas, melhorar orçamento, melhora dos postos de informação turística, criação de roteiros, manutenção e modernização dos espaços turísticos, melhorias no acesso em especial ao aeroporto, buscar capacitação, divulgar de maneira mais eficiente a cidade nas operadoras, agências de viagens e comunidade local e melhor, entre outras. 
O plano estratégico - Plano de Turismo - B foi classificado com 10 pontos, avaliado na escala de pontuação, como atendendo parcialmente aos critérios estabelecidos. O documento mesmo estando completo, apresentou uma baixa pontuação, comparado ao Plano de Turismo - A que não está completo, contendo apenas as fases de diagnóstico, estratégia e objetivos e que, certamente se o documento estivesse completo, teria realizado uma pontuação muito maior. No Quadro 2, pode-se notar que o plano analisado não pontuou, em nenhuma variável, a escala Atende (A) 2 pontos, pontuação que significa que o $\mathrm{PE}$ de turismo está metodologicamente adequado. Assim, pode-se concluir que o método utilizado neste documento precisa de uma reavaliação

O Planejamento Turístico do Plano de Turismo - B foi elaborado em 2007. No documento, as seguintes fases metodológicas do planejamento estratégico estão apresentadas: análise de cenário, objetivo geral, foco estratégico, eixos estratégicos, estratégia de implantação descrição das ações, cronograma.

$\mathrm{Na}$ etapa análise de cenário, os autores do Plano de Turismo - B avaliaram nove itens: atrativos, compras, hospedagem, alimentação, acessibilidade, sinalização, apoio ao turista, serviços de transporte, valor real, valor potencial, classificando o produto turístico como razoável. As necessidades levantadas nesta fase foram: a conscientização geral na cidade do trabalho que está sendo realizado e da importância do turismo para a economia do município; Conscientização turística; Reorganização e estruturação dos atrativos; Sinalização rodoviária e turística; Capacitação gerencial e operacional; Divulgação geral do município, focando seus principais produtos; Plano de marketing; Resgate da cultura e de eventos; Exploração de esportes náuticos; Criação de calendário completo integrado; Segurança pública, principalmente nos eventos e/ou horários diferenciados; Reorganização dos guias de turismo; Incentivo e criação de novos produtos; Transportes alternativos

As ações sugeridas foram: Gestão e Articulação; Promoção do Projeto; Conscientização; Capacitação em Gestão; Capacitação Operacional; Material Promocional; Participação em feiras e eventos; Eventos; Programa de Qualidade Turística; Empreendedores Turísticos; Diagnóstico Empresarial.

O Plano de Turismo - B pode contribuir para o diagnóstico do turismo municipal, no sentido de apresentar algumas deficiências no desenvolvimento da atividade. 
Conforme descreve Tomio (2000), apesar da importância do turismo na economia global e brasileira, os operadores turísticos, o setor público e as organizações turísticas pouco têm realizado em termos de planejamento de suas atividades, sendo o turismo um setor em que as decisões são intuitivas e improvisadas. Verificou-se que a realidade do planejamento turístico nos municípios de Santa Catarina, após pesquisa e análise dos planos, corresponde à afirmação do autor.

A pesquisa resultou num cenário atual desfavorável para o planejamento estratégico de turismo nos municípios pertencentes aos roteiros turísticos regionais de Santa Catarina, podendo ser considerado deficiente, pois dos 10 (dez) roteiros turísticos regionais pesquisados, apenas dois (dois) municípios apresentaram seus planos estratégicos.

Analisando os dados obtidos na pesquisa, observa-se que os fatores negativos são maiores que os positivos, no entanto salientamos que a existência de legislações do turismo e os impactos econômicos positivos do turismo, aliados ao planejamento no qual o setor público, a iniciativa privada e a comunidade participem de forma ativa, pode mudar esta situação, criando o turismo sustentável apropriado a todos: turista e população local. Quanto à análise dos planos, ficou evidente que o processo metodológico científico do planejamento estratégico do turismo é fundamental para bons resultados. Vimos que o Plano de Turismo - A aplicou metodologia SWOT, e a partir desta fase, seguindo todos os processos conforme os métodos sugerem poderão obter grande êxito no final do plano. Já no Plano de Turismo - B não estava explícito qual a metodologia utilizada. Os resultados não foram satisfatórios, tendo problemas de foco dos objetivos, e ainda não atendia a todos os problemas levantados no diagnóstico com ações que, aparentemente, são insuficientes para melhorar a qualidade do turismo naquela cidade.

\section{Considerações Finais}

O resultado da pesquisa atingiu o seu objetivo, o estudo verificou que o planejamento estratégico do turismo nos roteiros turísticos regionais de Santa Catarina necessita de direcionamentos. Dos documentos avaliados, um precisa de pequenas adequações metodológicas de planejamento estratégico e turístico, e o segundo necessita de uma revisão 
geral de objetivo e determinação de um método científico de planejamento para melhores resultados, porém é relevante a iniciativa já colocada em prática.

A conclusão geral da pesquisa é que existem alguns fatores que precisam ser melhorados, tais como: ausência de metodologia para o planejamento, necessidade de articulação entre a secretaria de turismo, o setor privado e a comunidade para elaboração de planos turísticos, bem como aumentar a execução de pesquisas e estudos turísticos para obtenção de dados fidedignos para a realização do planejamento estratégico, diminuir a dependência de recursos federais para planos e projetos, motivar a participação do setor privado no financiamento do setor turístico.

A solução para os problemas apresentados em curto prazo seria melhorar o alinhamento entre o planejamento estadual com o planejamento municipal. Outra ação seria que as secretarias de turismo contratassem, por meio de concurso público, profissionais da área, isto é, técnico de turismo e turismólogos, aptos para exercer o planejamento estratégico do turismo e o desenvolvimento do turismo sustentável. Outra iniciativa seria a articulação do governo federal e estadual dentro dos roteiros turísticos regionais, delegando pessoas para um processo de conscientização e sensibilização turística e, por fim, a mudança de postura política, priorizando os interesses coletivos.

Este estudo não objetiva esgotar a abordagem sobre planejamento. Novas investigações devem ser realizadas, no que diz respeito aos impactos gerados pela atividade turística, monitoramento e controle do turismo, investimentos para o setor, metodologias de planejamento turístico e estudo de casos de sucesso de planejamento estratégico do turismo.

\section{Referências}

BARRETTO, M. Planejamento responsável do turismo. Campinas: Papirus, 2005.

BARBETTA, P. A. Estatística aplicada às ciências sociais. Florianópolis: UFSC, 2001.

MINISTÉRIO DO TURISMO. Secretaria de Políticas de Turismo. Programa de Qualificação a Distância para o Desenvolvimento do Turismo: formação de gestores das políticas públicas do turismo/autoria do conteúdo técnico-científico Alexandre Panosso Netto, Francisco José Pereira da Silva, Luiz Gonzaga Godoi Trigo - Florianópolis: SEAD/FAPEU/UFSC, 2009. 312 p.

- Secretaria de Políticas de Turismo. Programa de Qualificação a Distância para o Desenvolvimento do Turismo: turismo e sustentabilidade: formação de redes e ação municipal para 
regionalização do turismo/Ministério do Turismo, coordenação Tânia Brizolla, Ana Clévia Guerreiro Lima. - [Brasília]: o Ministério: Florianópolis: SEaD/UFSC, 2008. 192 p.

. Disponível em: <www.mtur.gov.br>. Acesso em: 25 de jun. 2010.

BRASIL. Congresso Nacional. Decreto $n^{\circ}$ 11.771, de 17 de Setembro de 2008. Lei Geral do turismo. Brasília, 2008.

COOPER, C. et al. Tourism principles and practice. Melbourne, Austrália: Longman, 1993.

GIL, A. C. Como elaborar projetos de pesquisa. 4. ed. São Paulo: Atlas, 2002.

GOELDNER, C. R.; RITCHIE, J. R. B.; MCINTOSH, R. W. Turismo: princípios, práticas e filosofias. São Paulo: Bookman, 2002.

HOLANDA, N. Planejamento e projetos. Brasília: Instituto Nacional do Livro, 1974.

KOTLER, P. Administração de marketing: análise, planejamento, implementação e controle. 5. ed. São Paulo: Atlas, 1998.

OLIVEIRA, S. L. de. Tratado de metodologia científica: projetos de pesquisas, TGI, TCC, monografias, dissertações e teses. 2.ed. São Paulo: Pioneira Thomson Learning, 2001. 320 p.

NEVES, J. L. Pesquisa qualitativa: características, usos e possibilidades. Caderno de pesquisa em administração. FEA-USP. São Paulo, v. 1. n. 3. $2^{\circ}$ sem, 1996.

PLANO NACIONAL DE TURISMO. Disponível em: $<$ http://institucional.turismo.gov.br.pdf $>$ Acesso em: 15 jul. 2010.

SOL. Disponível em: <www.sol.sc.gov.br>. Acesso em: 15 jul. 2010.

SANTUR. Disponível em: <www.santur.sc.gov.br>. Acesso em: 15 d jul. 2010.

SANTA CATARINA. Decreto $N^{\circ} 13.792$ de 18 de julho de 2006.

2009

Plano Catarina 2020. Plano de marketing do Estado de Santa Catarina. Chias Marketing,

THOMPSON JR., A. A. \& STRICKLAND III, A. J. Planejamento estratégico: elaboração, implementação e execução. São Paulo: Pioneira, 2004.

TAVARES, M. C. Planejamento estratégico: a opção entre sucesso e fracasso empresarial. São Paulo: Harba, 1991.

REJOWSKI, M. Realidade versus necessidade da pesquisa turística no Brasil. Turismo em Análise. São Paulo: ECA/USP, v.9, n.1, 1998.

RUSCHMANN, D. et. al. A proteção ambiental como instrumento de estratégia empresarial - o caso da Ilha João da Cunha - SC. In: Anais do IV Encontro Nacional Sobre Gestão Empresarial e Meio Ambiente. São Paulo: USP/FGV, 1997, p. 92-106.

TOMIO, Dilson. Estrutura do Planejamento Estratégico do Turismo. Revisa de Negócios, v.. 5, $\mathrm{n}^{\circ} 3$ (2000). Disponível em: <http://proxy.furb.br/> Acesso em: 07 jan. 2011.

REVISTA. Disponível em: <Viagem e Turismo. http://viajeaqui.abril.com.br $>$. Acesso em: 10 jul. 2010.

ROTEIROS. Turísticos Regionais. Brasil - Santa Catariana. Editora Letras Brasileiras: Florianópolis,

RUDIO, F. V. Introdução ao projeto de pesquisa científica. 23. ed. Petrópolis: Vozes, 1986.

WOILER, Sansão. Projetos: planejamento, elaboração e análise. São Paulo: Atlas, 1996. 
WORLD TRAVEL \& TOURISM COUNCIL. Viagens e turismo: impacto econômico - Santa Catarina. Disponível em: <http//: www.wttc.org>. Acesso em: 21 dez. 2010.

Recebido em: 05/05/2011

Aprovado em: 29/11/2011 (1 ${ }^{\mathrm{a}}$ versão) $23 / 12 / 2012$ (2 ${ }^{\mathrm{a}}$ versão) 